\title{
Optimization of Process Parameters in Deep Drawing Process Based on Orthogonal Experiment Method
}

\author{
Liwen Tian $^{1,2, a}$, Changfeng Men ${ }^{2, b}$, Qiang $\mathrm{Yu}^{2, \mathrm{c}}$ \\ ${ }^{1}$ Tianjin Key Laboratory of High Speed Cutting \&Precision Machining, Tianjin 300222, China \\ ${ }^{2}$ Tianjin University of Technology and Education, Tianjin 300222, China \\ asxpytlwen@163.com, ${ }^{\mathrm{b}}$ menzi6210@sohu.com, ${ }^{\mathrm{c} y}$ uqiang95@yeah.net
}

Keywords: Deep drawing experiments, finite element simulation, orthogonal test, optimal process parameters

\begin{abstract}
Thinning is one of the main reasons that caused parts scrap, the geometry size is not accurate and the finished part has a poor quality in the process of cold stamping. Based on the orthogonal experiment method, LS-DYNA software is used in this paper to carry on the deep drawing process of box parts with finite element simulation. The thickness of the thinnest place is selected to indicate the quality of the finished parts and the main effect of technical parameters of deep drawing process which makes the variation in thickness of the thinnest place of box parts. The analysis shows that the most important factor which affects the thickness of the minimum is blank holder force, the second is the concave die entrance radius, the influence of Punch velocity and the radius is minimal. Thus the optimal process parameters of blank-holder force is $200 \mathrm{KN}$, die entrance radius is $4 \mathrm{~mm}$, combined with punch radius $5 \mathrm{~mm}$, punch velocity $2000 \mathrm{~mm} / \mathrm{s}$.
\end{abstract}

\section{Introduction}

Deep drawing is a cold stamping process that use the die make rough or semi-finished into an opening hollow parts [1]. The material thickness of various parts is changed along with the drawing process, but the change process is not uniform. The maximum change occurs in the outer edges[2].When the process finished, the most thick part is the edge of the finished part and Look inside look thinner, but at the bottom, the friction effect that prevent material elongation deformation and make the bottom material becomes thinning smaller where is the bi-directional tensile stress, and in the side wall area it is the Unidirectional tensile stress which often caused the series crack[3-4].So in the process of drawing thickness mainly concentrated in the part of fillet and the side wall of the cylinder part[5]. Wall thickness is an important quality index of the drawing [6]. It is very important to make sure the reasonable process parameters and predict the forming defects, which studies the influence of process parameters on the deep drawing pieces of wall thickness.

In this paper, LS-DYNA software is used to simulate the process of deep drawing for box shaped part, Forming limit diagram and thickness distribution of cloud image can be also achieved by this method. Through the orthogonal experiment design method, the optimization of drawing process parameters for the minimum thickness is done to confirm the plan of final drawing process.

\section{Deep drawing forming finite element model}

Test material (SPCC) for high strength steel plate, thickness of $1 \mathrm{~mm}$, and the uniaxial tensile material mechanics performance index is shown in Table 1. Material mechanics performance parameter values obtained through uniaxial tensile mechanical properties test.

Using UG which is three-dimensional modeling software to model box type parts which is shown in Fig.1, then import to LS-DYNA which is the sheet metal forming analysis software. Then division of grid, the result is shown in Fig.2. There are 18796 Sheet metal node and 33587 die node. Checking the grid, confirm the meshless defects. BINDER is isolated from the DIE, quickly set up drawing types are Single Action and the Up Tool Available. Automatically define DIE and BINDER respectively. Adopted Auto Assign, concave die, demonstration of deep drawing process, 
obtained from the processor after deep drawing forming limit diagram. By using Auto Assign, get the die drawing, and carry on the deep drawing process of demonstration, obtain the forming limit diagram from the post processor and the thickness changes.

Table 1 Uniaxial tensile performance parameters

\begin{tabular}{|c|c|c|c|c|c|}
\hline $\begin{array}{c}\text { Yield } \\
\text { strength } \\
\sigma_{s}(M p a)\end{array}$ & $\begin{array}{l}\text { Modulus of } \\
\text { elasticity } \\
E(G P a)\end{array}$ & $\begin{array}{c}\text { Poisson's } \\
\text { ratio } \\
v\end{array}$ & $\begin{array}{l}\text { Hardening } \\
\text { index } \\
n\end{array}$ & $\begin{array}{l}\text { Strengthening } \\
\text { coefficient } \\
K(M P a)\end{array}$ & $\begin{array}{c}\text { Thick anisotropic } \\
\text { index } \\
r\end{array}$ \\
\hline 139.58 & 160 & 0.25 & 0.262 & 467.01 & 1.648 \\
\hline
\end{tabular}

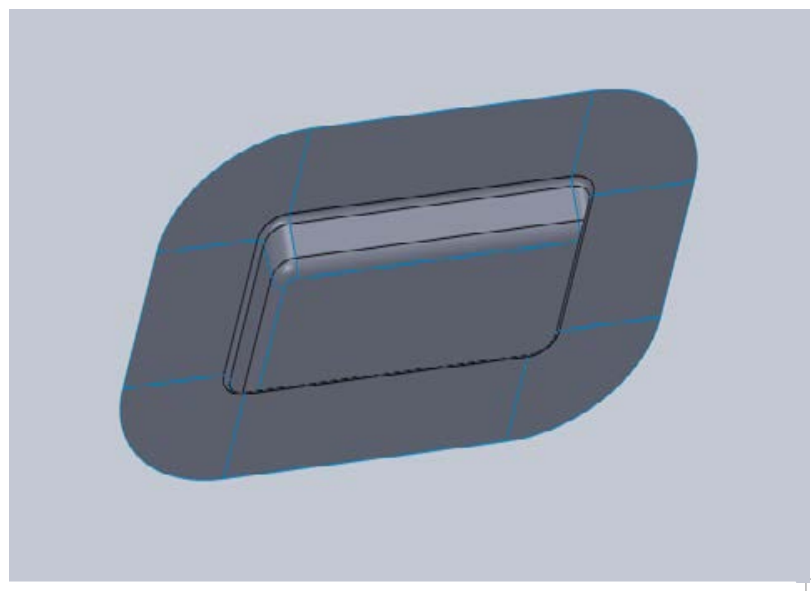

Fig.1 Geometric model

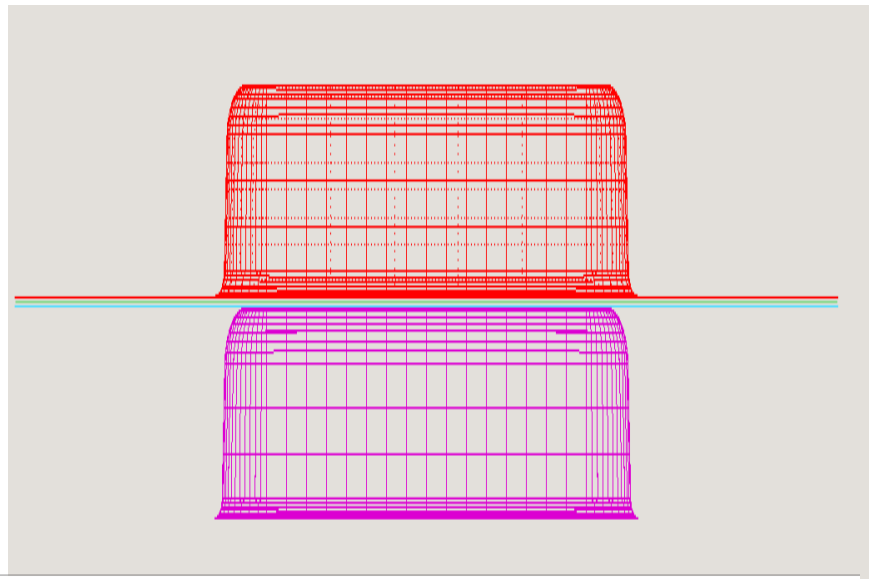

Fig.2 Meshing

\section{Orthogonal test design}

Select test factors and levels

Orthogonal experiment design method based on mathematical theory, professional knowledge and practical experience as the foundation; make full use of standardized orthogonal table to arrange testing scheme, and calculate and analysis the test results. Orthogonal experiment is taken part instead of a comprehensive test method, the selected typical sites for test, through the typical experimental results of the analysis; understand the comprehensive test, in order to realize the optimization of process. Choosing representative sites, therefore, becomes the key to the orthogonal experiment.

Stretch forming process parameters: punch velocity, blank holder force, die entrance radius, punch radius are defined as test factors, and referred them as factors A, B, C, D, and assuming that there is no interaction between different affecting factors. Within the scope of the various factors, each factor of uniform take 3 level, as shown in Table 2.

Table 2 Level test factors

\begin{tabular}{ccccc}
\hline \multirow{2}{*}{ Level } & \multicolumn{4}{c}{ Factors } \\
\cline { 2 - 5 } & $\begin{array}{c}\text { Blank holder } \\
\text { force } \\
\mathrm{A}(\mathrm{KN})\end{array}$ & $\begin{array}{c}\text { Die entrance } \\
\text { radius } \\
\mathrm{B}(\mathrm{mm})\end{array}$ & $\begin{array}{c}\text { Punch } \\
\text { radius } \\
\mathrm{C}(\mathrm{mm})\end{array}$ & $\begin{array}{c}\text { Punch movement } \\
\text { speed } \\
\mathrm{D}(\mathrm{mm} / \mathrm{s})\end{array}$ \\
\hline 1 & 300 & 3 & 3 & 2000 \\
2 & 400 & 4 & 4 & 3500 \\
3 & 500 & 5 & 5 & 5000 \\
\hline
\end{tabular}

Analyze the practical situation of test and determine evaluation index

Sheet metal thinning is the result of tensile stress. From the point of engineering practice, for stamping parts, most of the sheet thickness decreased by $4 \% \sim 20 \%$ is generally acceptable [7]. Because the high strength steel has high strength and low elongation, material is difficult to yield, therefore, to produce stable plastic deformation. Control sheet thinning is one of the most important 
aspects of the mold design [8] .Therefore; test index is identified as the end of the box parts in deep drawing thickness minimum time.

\section{The choice of orthogonal table}

Orthogonal table has two characteristics: 1 ) the frequency of different numbers in each column is equal. 2) In any two columns in the number of lateral, the frequency of each number is equal. Orthogonal table must satisfy these two characteristics, if one of them is not satisfied, it is not orthogonal table [9].

According to 'contains all the factors and have a minimum number of experiments' orthogonal table selection principle, take the $\mathrm{L}_{9}\left(4^{4}\right)$, 4 factors 3 levels orthogonal table, maximum thickness of the thinnest place test index. The results are shown in Table 3.

Table 3 Orthogonal test and the results

\begin{tabular}{|c|c|c|c|c|c|}
\hline \multicolumn{5}{|c|}{ Scheme of simulation experiment } & Consequence \\
\hline $\begin{array}{c}\text { Test } \\
\text { number }\end{array}$ & $\begin{array}{c}\text { Factor A } \\
(K N)\end{array}$ & $\begin{array}{l}\text { Factor B } \\
(\mathrm{mm})\end{array}$ & $\begin{array}{l}\text { Factor C } \\
(\mathrm{mm})\end{array}$ & $\begin{array}{c}\text { Factor D } \\
(\mathrm{mm} / \mathrm{s})\end{array}$ & $\begin{array}{l}\text { The minimum thickness } \\
(\mathrm{mm})\end{array}$ \\
\hline 1 & 300 & 3 & 3 & 2000 & 0.707671 \\
\hline 2 & 300 & 4 & 4 & 3500 & 0.734116 \\
\hline 3 & 300 & 5 & 5 & 5000 & 0.712265 \\
\hline 4 & 400 & 3 & 4 & 5000 & 0.748981 \\
\hline 5 & 400 & 4 & 5 & 2000 & 0.802006 \\
\hline 6 & 400 & 5 & 3 & 3500 & 0.721915 \\
\hline 7 & 500 & 3 & 5 & 3500 & 0.735182 \\
\hline 8 & 500 & 4 & 3 & 5000 & 0.698482 \\
\hline 9 & 500 & 5 & 4 & 2000 & 0.757513 \\
\hline
\end{tabular}

\section{Optimization analysis of the main process parameters}

The method of optimize process parameters is poor analysis. The poor is the difference between the maximum and minimum value which is the average value of parameters test under different levels. The poor calculation factor levels after the results are shown in Table 4.

The $K i$ is the average of the factor level $I$. According to the $K i$ evaluation the column $I$ factors corresponding to the optimal level. $R$ is factors in the three levels of the difference between the maximum and minimum values, namely the poor factor levels. $R$ reflect the test results' volatility of the column $I$ factors as a result of level changes of volatility, the greater the $R$ value, the bigger that the factors influence on indexes, if adjusting the values of process parameter, the thickness of box parts have a big change. The smaller the $R$ value, the factors that affect the change of the thickness will lower.

Table 4 Factors Level poor analysis of factors lever

\begin{tabular}{ccccc}
\hline Factors & $\mathrm{A}$ & $\mathrm{B}$ & $\mathrm{C}$ & $\mathrm{D}$ \\
\hline$K_{1}$ & 0.7180171 & 0.730611 & 0.729356 & 0.735077 \\
$K_{2}$ & 0.7569812 & 0.744215 & 0.746870 & 0.730404 \\
$K_{3}$ & 0.7303923 & 0.717237 & 0.749165 & 0.719909 \\
$R$ & 0.0389642 & 0.026977 & 0.019809 & 0.015168 \\
\hline
\end{tabular}

As shown in Table 4, the most important factor which affects the thickness of the minimum is blank holder force, the second is the concave die entrance radius, the influence of Punch velocity and the radius is minimal. The blank-holder force is $400 \mathrm{KN}$, die entrance radius is $4 \mathrm{~mm}$, Punch radius is $5 \mathrm{~mm}$, Punch velocity of $2000 \mathrm{~mm} / \mathrm{s}$. Get the optimal level of combination is $A_{2}, B_{2}, C_{3}$, $\mathrm{D}_{1}$.Fig.3,Fig.4 respective thickness distribution and the forming limit under the optimal process parameters combination. 


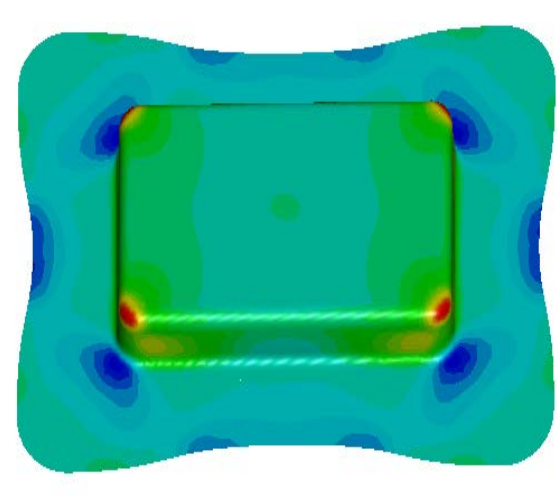

Fig. 3 Thickness distribution

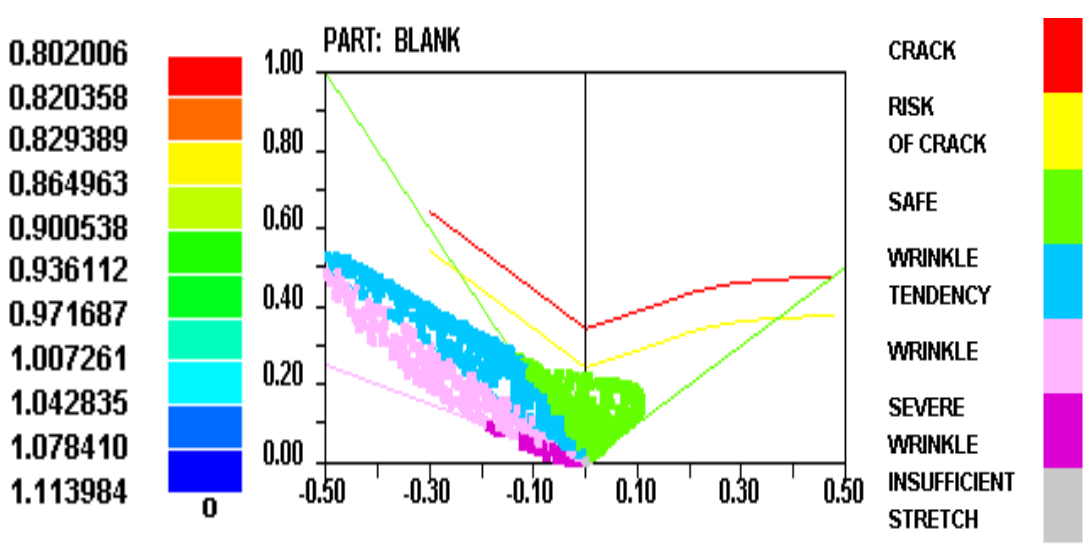

Fig.4 Forming limit diagram

In order to directly obtain the optimal level combination and using Factor Evaluation Indicator Diagram to analyze. Using factor level as the abscissa, evaluation index of the mean as the ordinate, relation picture is shown in the Fig.5. It can be seen from the Fig. $6, A_{2}, B_{2}, C_{3}, D_{1}$ respective the optimal level combination of four factors.

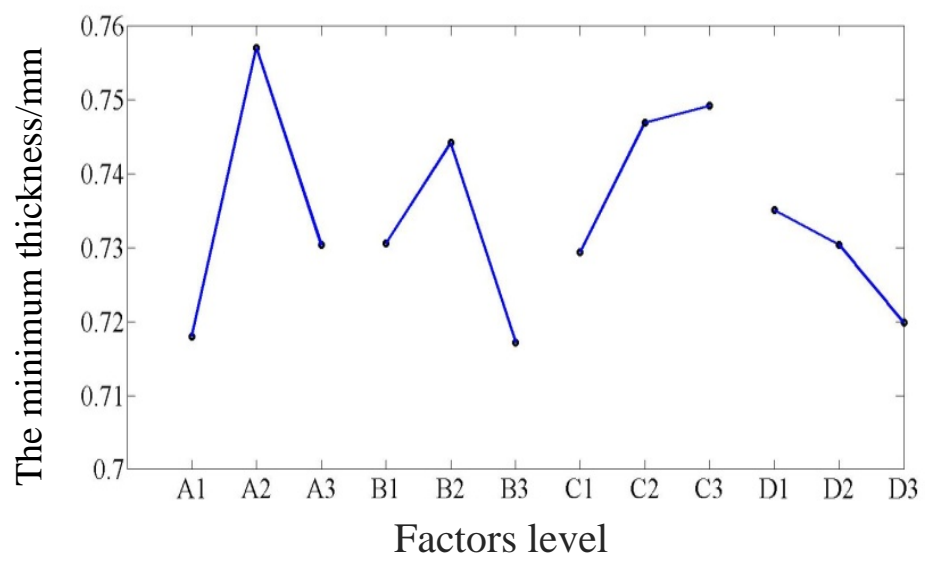

Fig.5 Minimum thickness influence factors and index

\section{Summary}

(1)In the process of deep drawing, four punch fillet subjected to biaxial tensile stress, it make the result in the thickness changing is serious. But only a part of flange and wall part subjected bidirectional compressive stress, so it makes thickness thicker, the part of bottom almost no changed, the same as the simulation results.

(2)According to the orthogonal experiment results on box parts in deep drawing process, The primary and secondary order of the main technological parameters on the factors of thickness change influence: the most important factor which affects the thickness of the minimum is blank holder force, the second is the concave die entrance radius, the influence of Punch velocity and the radius is minimal. The process parameters for optimizing combination are: blank-holder force of $400 \mathrm{KN}$, die entrance radius of $4 \mathrm{~mm}$, Punch radius of $5 \mathrm{~mm}$, Punch velocity of $2000 \mathrm{~mm} / \mathrm{s}$. At this time the thickness of the box type a minimum of $0.802006 \mathrm{~mm}$, reduction ratio is less than $20 \%$ get the optimal level of combination is $A_{2}, B_{2}, C_{3}, D_{1}$. The thickness of the box type parts have been improved significantly. 
(3)Blank-holder force is the main reason which caused the sheet thickness changed in the process of deep drawing, if it is too big, it will make the sheet metal ripping, on the contrary, if it is too small, it may make sheet wrinkling. Therefore we should choose the suitable blank-holder force. Die entrance radius are the secondary factors affecting the thickness of the sheet metal. If the radius is too small, it increases the metal flow resistance, thus increasing the tendency of cracking. Appropriate increase the radius can improve die life, but with the increase of radius, blank is pulled into the quantity can be increased significantly; it can make the box inner side prone to wrinkling. The impact of punch velocity and punch radius is smaller. Therefore in the process of deep drawing mold, selecting the appropriate process parameters can make the thickness of the plastic parts to get a better improvement.

\section{Reference}

[1] B. M .Wang, W. X. Song, Q. T. Liu, etc., Based on the orthogonal experiment the battery cover of thin-wall plastic parts molding process parameters optimization, Light industry machinery ,2014,pp.2894-2895.

[2] Q. Zhou, S. Gong, Z. F. Hu, Based on orthogonal experiment method of body side impact performance optimization, Beijing automotive, 2012, pp.10-14.

[3] X. B. Zhang, Plating coating thickness changes in sheet deep drawing process influence factors analysis, New technology and new technology,2014,pp.7-10.

[4] M. L. Liu, Variance analysis of orthogonal experimental design, master's thesis of Chongqing University, 2011.

[5] L. Zhang, H. Yu, B. Yi, J. Tang, Improving the precision of numerical simulation analysis of sheet metal forming, Mold industry ,2013,pp.59-65.

[6] S. S. Han, The influence of tool geometry on friction be Havier in sheet metal forming, Journal of Materials Processing Technology, 2009, pp.129-133.

[7] C. J. Su, T. Yu, Sheet Metal Forming Analysis and Application, National Defense Industry Press, Beijing,2011.

[8] F. Z. Li, Y. B. Zhang, X. F. Wang, J. Y. Wang, Design and application of the sheet metal forming CAE-based on DYNAFORM, Beijing University of aeronautics and astronautics press, Beijing, 2010.

[9] C. H. An, Based on ANSYS and roadway bolting optimization orthogonal experiment method, Journal of Zhengzhou institute of light industry,2014,pp. 50-54. 